\title{
Ícones para mapas de riscos: uma proposta construída com os trabalhadores 1
}

\author{
Icons for occupational risk maps: a proposal \\ developed with workers 1
}

Luiz Augusto Facchini 2 Marinel Mór Dall'Agnol 2 Anaclaudia Gastal Fassa 2 Rosângela da Costa Lima 2

\footnotetext{
1 Este artigo integra o Projeto Trabalho e Saúde na Indústria da Alimentação de Pel otas, que tem recebido apoio das seguintes instituições: Consel ho Nacional de Desenvolvimento Científico e Tecnológico CNPq, Organização Panamericana da Saúde OPAS, Fundação de Amparo à Pesqui sa do Estado do Rio Grande do Sul - FAPERGS e Fundação Jorge Duprat Figueiredo de Segurança e Medicina do Trabalho (Fundacentro).

2 Departamento de Medicina Social, Faculdade de Medicina, Universidade Federal de Pelotas. C. P. 464, Pel otas, RS

96.001-970, Brasil. marinel@minerva.ufpel.tche.br http://www.ufpel.tche.br/ me dicina/strab/strab.htm
}

Abstract The methodology known as the workers' model was used to design risk maps in a study performed in the food-processing industry in Pelotas, in the State of Rio Grande do Sul in southern Brazil. The various types of occupational risks were initially represented by geometric figures, with a size gradient to represent intensity. Joint investigation of these icons showed that they had little meaning for the workers. In addition, risks from a same group (physi cal, chemical, etc.) but with different impact on health were grouped, thus missing the specificities of exposure. As an alternative, and starting from workers' own risk perceptions, a set of risk icons was devel oped. The study was done in three steps involving sixty workers, who proposed and sel ected the most suitablesymbols, which were subsequently printed on stickers using silk-screen so that the workers could glue them on the risk maps. Each risk is represented by one icon, and intensity of exposure is defined by color. This paper presents the icons and the process involved in designing them.

Key words Icons; Working Risks; Workload; Worker's Model; Worker's Health

Resumo Em estudo realizado na indústria da alimentação de Pel otas, utilizou-se a metodologi a do Model o Operári o para elaborar mapas de riscos. Inicialmente, representaram-se os grupos de riscos por meio de figuras geométricas, com graduação de tamanho para caracterizar a intensidade. Notou-se que estas ti nham pouco si gni ficado para o trabalhador. Além disso, com a agregação de riscos com diferentes impactos sobre a saúde, perdia-se o detal hamento da exposi ção. Como alternativa, desenvolveu-se uma iconografia, partindo da visão do trabalhador. A investigação foi qualitativa e realizou-se em três etapas com sessenta trabalhadores, que sugeriram e seleci onaram os ícones mais adequados. A seguir, utilizando-se processo serigráfico, estes foram digitalizados e impressos em adesi vos para que o próprio trabal hador pudesse colá-los no mapa de riscos. Cada risco é representado por um ícone e a intensi dade de exposi ção é expressa pela sua cor. Este artigo apresenta estes ícones e o processo desenvolvi do para a sua el aboração. Palavras-chave Í cones; Riscos Ocupacionais; Cargas de Trabalho; Model o Operári o; Saúde do Trabalhador 


\section{Introdução}

A representação dos riscos ocupacionais ganha importância no País com a nova legislação da área de saúde do trabalhador que exige das empresas a implantação do Programa de Prevenção de Riscos Ambientais, incluindo a obrigatoriedade da elaboração de mapas de riscos (MT, 1994). Proposto pelos operários italianos no final da década de 60 , na metodologia que ficou internacionalmente conhecida como Modelo Operário, o mapa é a expressão gráfica da distribuição dos riscos ocupacionais em um processo de trabal ho particular. Utilizando círculos com diferentes cores e tamanhos, o mapa resume os riscos presentes nos locais de trabalho. As cores dos círculos indicam os grupos de riscos segundo sua natureza, por exemplo, físicos (ruído, vibração e altas temperaturas), químicos (substâncias químicas e fumaças), e o tamanho indica a importância destes riscos no local de trabalho (Odonne, 1977; Laurell, 1984; Facchini et al., 1991; Facchini, 1994).

Em Pelotas, o método vem sendo utilizado desde 1989, especialmente em função de estudos desenvolvidos em colaboração com os trabalhadores e suas organizações sindicais (Facchini et al., 1991; 1992a e b; 1993a e b; 1995a e b). Neste período, processou-se uma adaptação de seus princípios basilares, principalmente em função da necessidade de padronização dos dados de seis processos de produção diferentes, no estudo da indústria da alimentação (Facchini, 1993). À semelhança do modelo original (Oddone, 1977) e de suas adaptações acadêmicas (Laurell, 1989) ou legais (MT, 1994), na representação gráfica dos riscos ocupacionais, utilizaram-se primeiramente figuras geométricas com cores e tamanhos distintos conforme a natureza e a intensidade destes riscos (Facchini et al., 1992a e b). Entretanto, observou-se que estas figuras tinham pouco significado para os trabalhadores. Além disso, ao classificálos segundo sua natureza, agrupa-se em uma mesma figura riscos com impactos diferentes sobre a saúde, havendo uma perda no detalhamento ou na especificação da exposição.

Por esta razão, desenvolveu-se uma iconografia que, partindo da visão dos trabalhadores, procura não só facilitar a compreensão dos riscos ocupacionais, mas também representar de modo mais preciso as exposições identificadas. Neste artigo, serão apresentados o processo desenvolvido e os resultados obtidos, ou seja, os ícones que estão sendo utilizados para representar os riscos ocupacionais na indústria da alimentação de Pelotas.

\section{Metodologia}

O processo de construção dosícones desenvolveu-se em três etapas, com a participação de sessenta trabalhadores que procuraram os serviços de saúde e de assistência jurídica do Sindicato dos Trabalhadores das Indústrias e Cooperativas da Alimentação de Pelotas, no primeiro semestre de 1992.

As duas primeiras etapas foram dedicadas ao desenvolvimento propriamente dito dos ícones, sendo realizadas em grupos com três trabal hadores. A etapa final foi dedicada à avaliação individual pelos trabalhadores dos ícones desenvolvidos. Nas três etapas foi fornecida a seguinte informação aos trabal hadores: “Estamos fazendo um estudo para avaliar os riscos à saúde do trabal hador. Assi m, queremos criar figuras para estes riscos de forma que qual quer trabal hador, ao vêlas, possa saber o seu significado".

A seguir estão descritos os processos desenvolvidos e os resultados obtidos em cada uma das etapas.

Primeira etapa:

captando sugestões para ícones

Nesta etapa, apresentou-se uma lista com os riscos ocupacionais identificados no estudo sobre a indústria da alimentação a seis grupos de três trabalhadores, formulando-se a seguinte solicitação: "Gostaríamos que tu desses a tua idéia sobre como representar estes riscos".

A partir da discussão nestes grupos, reuniram-se as várias sugestões para cada um dos 25 riscos apresentados, formando-se um banco inicial de 47 imagens. Um desenhista participou das reuniões para melhor captar as sugestões dos trabal hadores, que foram cuidadosamente desenhadas em tamanho 10 por 12 centímetros.

\section{Segunda etapa: selecionando ícones}

Apresentaram-se as imagens esboçadas na etapa anterior a outros seis grupos de três trabaIhadores. A solicitação foi a seguinte: “Gostaríamos quetu desses a tua idéia sobre o que cada figura significa". Nesta etapa, procurou-se selecionar, dentre os ícones elaborados, aquele com maior significação para cada carga entre os operários entrevistados.

Após a seleção dos ícones mais significativos, estes foram redesenhados e padronizados, buscando-se aprimorar sua capacidade de comunicação. A seguir, foram digitalizados em microcomputador através de um scanner de 
mão, reduzindo-se seu tamanho a $2 \mathrm{~cm}^{2}$ no software Corel Draw. Estas dimensões foram consideradas adequadas para a visualização dos ícones em mapas de riscos destinados à apresentação como pôster ou mural.

Terceira etapa:

Correlacionando ícones e riscos

Os ícones selecionados na segunda etapa foram apresentados em planilhas a 24 trabalhadores. Solicitou-se que cada um correlacionasse os ícones constantes em uma coluna com as denominações dos riscos ocupacionais registrados em outra. A solicitação foi a seguinte: "Gostaríamos que tu tentasses relacionar as figuras com os riscos".

Nesta fase, foram definidas as figuras a serem utilizadas, uma vez que os trabalhadores reconheceram satisfatoriamente os ícones propostos.

Em seguida, foi realizada a finalização gráfica com a padronização da figura humana e do tamanho do desenho e retirada de elementos desnecessários à compreensão das figuras.

Os ícones foram impressos em serigrafia. Utilizou-se papel adesivo, para que o próprio trabalhador pudesse colá-los no mapa de riscos durante as reuniões do Modelo Operário.

Para caracterizar a intensidade dos riscos ocupacionais vêm sendo utilizadas as cores rosa, para exposição alta; violeta, para intermediária e lilás, para baixa. Estas cores são expressas na linha do desenho, em um fundo branco fosco.

Também foram impressos ícones com 1 $\mathrm{cm}^{2}$, para mapas em tamanho ofício utilizados em relatórios técnicos ou publicações.

\section{Resultados}

A seguir, descreve-se a freqüência das correlações positivas obtidas na terceira etapa. Entre as cargas ambientais investigadas, temperatura inadequada, umidade, iluminação, vibração, ventilação, ruído, gases e vapores, poeira e fumaça e substâncias químicas foram reconhecidas em mais de $90 \%$, e radiação, em $54 \%$ das vezes em que os ícones foram apresentados.

Entre as cargas relacionadas à atividade, trabalho físico pesado, não poder conversar com os colegas, pressão da chefia, intervalos e horas-extras, trabalho perigoso e situação de emergência foram corretamente associados em cerca de $90 \%$ das vezes. Houve em torno de $80 \%$ de acerto na correlação de posição incômoda, risco de acidentes, não poder afastar-se do posto de trabalho, turno rotatório, trabalho não criativo e não poder desenvolver atividades de defesa coletiva com seus ícones. As cargas com menor freqüência de acerto foram atenção constante $(71 \%)$, monotonia e repetitividade (63\%) e trabalho em grande velocidade (58\%).

Observou-se que a correlação foi correta em 507 das seiscentas vezes em que os ícones foram apresentados a estes trabal hadores na terceira etapa, correspondendo a $85 \%$ de acerto, e todas as cargas foram corretamente associadas em pelo menos metade das vezes. Assim, considerou-se este índice de acerto satisfatório para a identificação dos riscos através destes ícones.

Os ícones são apresentados na Figura 1, com a legenda de cores utilizadas para expressar a intensidade de exposição. A Figura 2 apresenta um exemplo de utilização dos ícones no mapa de riscos do setor de envasamento de uma indústria de laticínios.

\section{Discussão}

A utilização de mapas é uma das formas mais efetivas de representação dos riscos ocupacionais, constituindo-se em um elemento básico para a estruturação de planos de prevenção dos danos à saúde dos trabalhadores (Beccastrini \& Faillace, 1982). Neste sentido, a legislação que estabelece a obrigatoriedade da elaboração de mapas de riscos pelas empresas significou um avanço importante para o País, pois ajuda a evidenciar as condições perigosas à saúde dos trabalhadores, historicamente escondidas ou dissimuladas pela lógica capitalista da acumulação.

Entretanto, alguns aspectos relacionados à representação dos riscos ocupacionais precisam ser discutidos mais detal hadamente. A utilização de círculos de cores diferentes para representar grupos de riscos segundo sua natureza - físicos, químicos e ergonômicos - parece acarretar um duplo prejuízo na comunicação com o trabal hador: a perda na especificidade da exposição e a menor significação destes símbolos gráficos. Neste caso, a utilização de ícones específicos para cada risco parece ser uma alternativa eficaz para este problema de representação gráfica.

Para a adequada construção dos ícones, é fundamental que os trabal hadores tenham vivenciado os riscos a serem representados e que se valorize sua percepção no processo iconográfico, ou seja, na identificação e seleção dos ícones. Neste estudo, priorizou-se a realização de grupos nas duas primei ras etapas, para propiciar a troca de idéias entre os trabal hadores, 
Figura 1

Ícones para mapas de riscos.

Riscos relacionados ao ambiente de trabalho

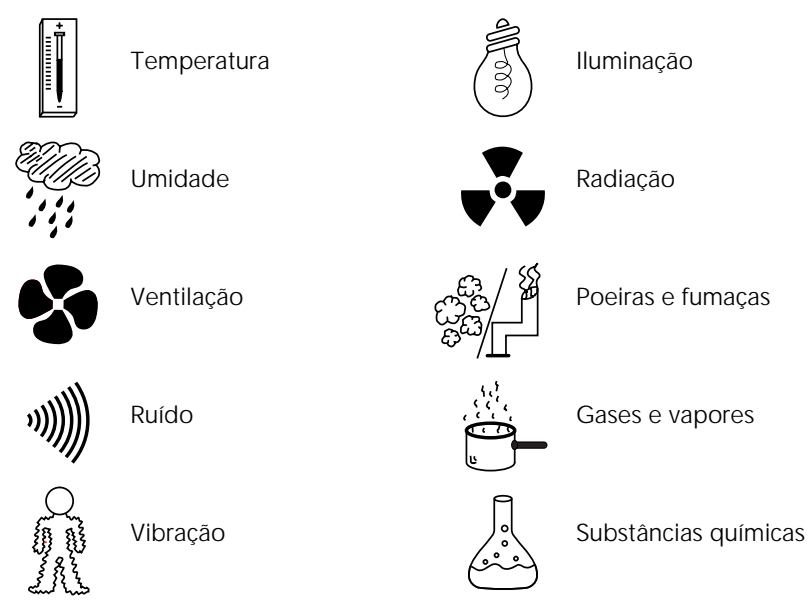

Riscos relacionados à atividade

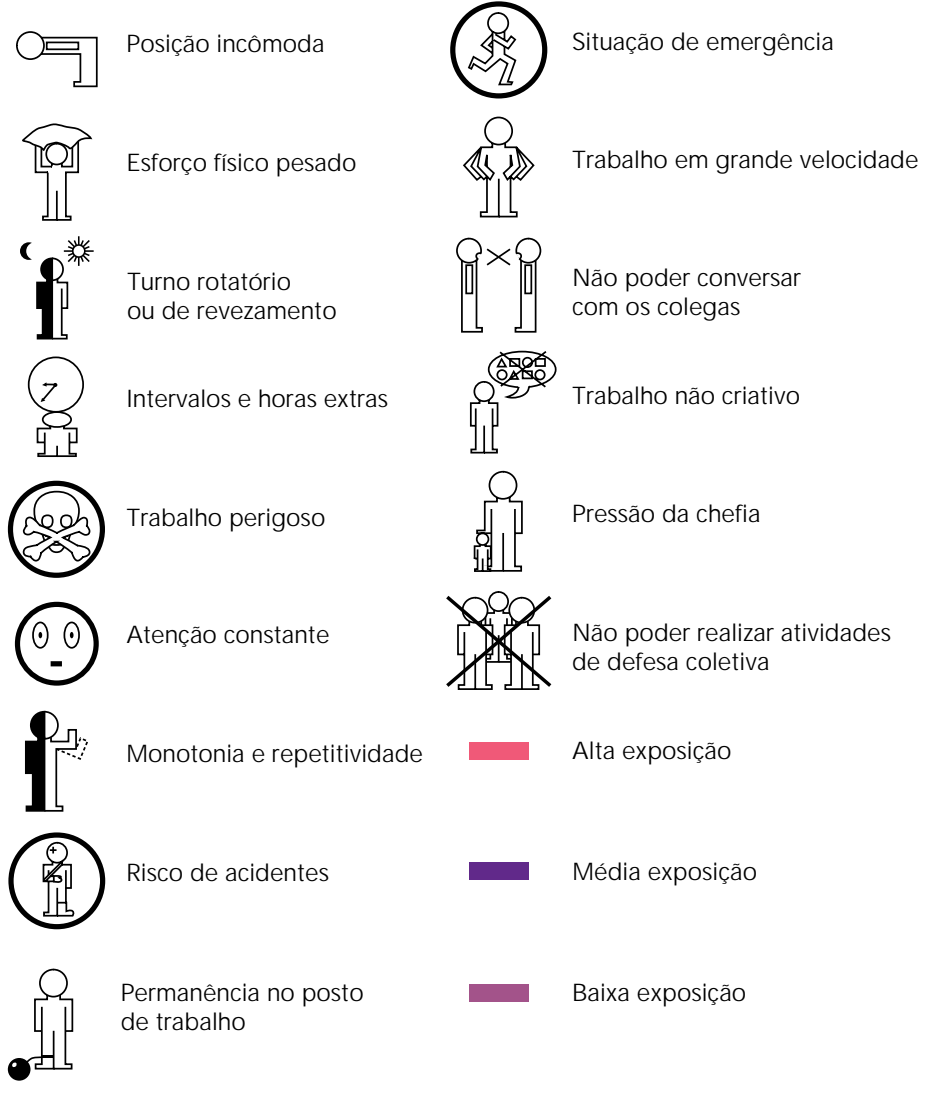

reforçando o embasamento cultural das sugestões. Além disso, para que haja um reforço da associação entre ícone e risco, é desejável que as figuras que serão utilizadas sejam amplamente divulgadas entre os trabalhadores.

A proposta apresentada integra uma avaliação criteriosa de todo um ramo produtivo - a indústria da alimentação de Pelotas -, para a qual utilizaram-se dois enfoques metodológicos distintos, ambos fundamentados na percepção operária. O primeiro enfoque foi um inquérito epidemiológico que caracterizou a população trabalhadora, os riscos ocupacionais e a morbidade mais freqüente em 15 indústrias diferentes. $O$ segundo enfoque baseou-se em uma adapatação do Modelo Operário, sendo os riscos ocupacionais mapeados em seis processos de trabalho distintos.

Observou-se que a opção por ícones adesivos possibilita o maior envolvimento dos trabal hadores no mapeamento dos riscos. Esta alternativa incentiva a participação do trabalhador na confecção do mapa de riscos, inclusive em sua versão final, uma vez que é ele próprio quem cola o ícone sobre o layout do processo de trabal ho previamente desenhado, definindo o local exato de ocorrência do risco. Esta estratégia, além de reforçar os princípios do Modelo Operário de valorização da experiência operária e não-delegação, torna as reuniões mais participativas e dinâmicas.

Apesar das vantagens referidas, al guns aspectos precisam ser considerados para plena utilização desta proposta. Certamente, um único conjunto de ícones não é capaz de representar os riscos de todas as atividades produtivas. Esta situação pode ocorrer inclusive em diferentes indústrias dentro de um mesmo ramo de produção, onde a variabilidade na prevalência dos riscos e diferenças na percepção dos trabalhadores precisam ser levadas em conta.

Por exemplo, o ícone para radiação esteve entre os menos reconhecidos na proposta apresentada, embora tenha-se utilizado o símbolo internacional, pois este não é um risco importante no ramo produtivo em questão. Além disso, houve dificuldade de reconhecimento dos ícones que representavam riscos sem materialidade externa ao corpo do trabaIhador, como trabal ho em grande velocidade, monotonia e repetitividade, que são de difícil representação gráfica.

A seleção das cores utilizadas para estabelecer intensidade dos riscos também deve estar sob constante investigação. Optou-se por desenhar o ícone em cores, sobre fundo branco e fosco, porque a utilização de ícones com o fun- 


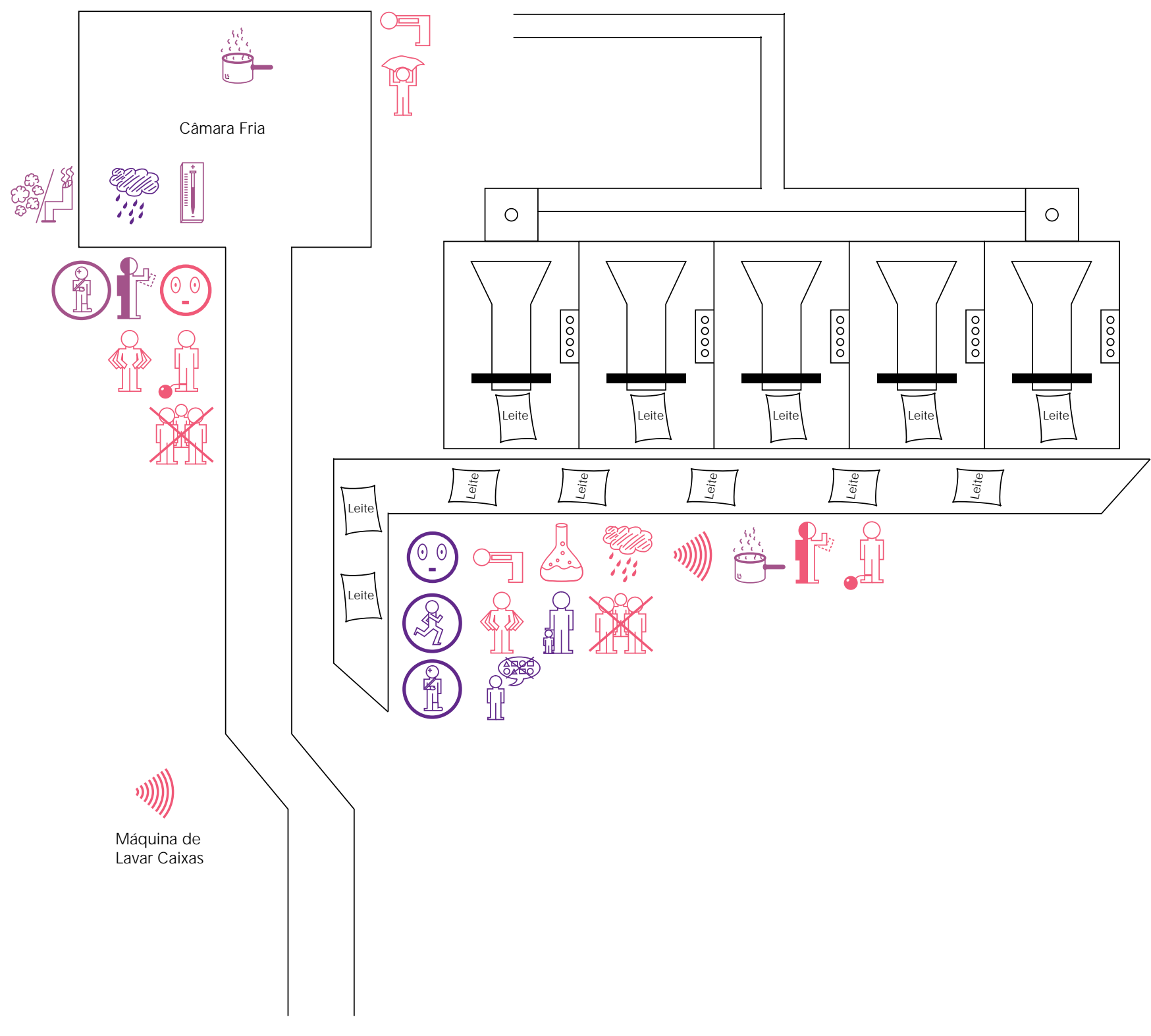

do colorido produzia figuras secundárias, confundindo o layout do processo de trabalho.

A proposta inicial para as cores foi um dégradé para expressar a gradação da intensidade da exposição, ou seja, a tonalidade mais forte (violeta) representaria a maior exposição. Entretanto, os trabalhadores atribuíram ao rosa a exposição mais intensa, pois esta cor aproxima-se do vermelho, que costuma ter a conotação de perigo. A exposição média passou a ser expressa pelo violeta, e a baixa, pelo lilás. Ao observar-se que o dégradé proposto não foi adequado, pretende-se utilizar cores com diferenças marcantes, como por exemplo, vermeIho para alta exposição, azul para média e verde para baixa. A pouca definição das cores claras, como o amarelo, sobre o fundo branco do ícone, dificulta o uso destas tonalidades.

Ao concluir, é importante enfatizar que os ícones propostos vêm sendo utilizados com êxito não apenas na indústria da alimentação de Pelotas, mas também em outros estudos envolvendo trabalhadores de outras atividades industriais e, inclusive, de outros setores eco- 
nômicos. Ao individualizar os riscos presentes no processo de trabalho e indicar uma certa intensidade de exposição, os ícones contribuem para orientar tanto atividades de prevenção e controle realizadas pelas empresas, quanto sua vigilância e/ ou fiscalização.

\section{Referências}

BECCASTRINI, S. \& FAILLACE, R., 1982. Prevenzione nei Luoghi di Lavoro e Potere Locale. Roma: Edizioni delle Autonomie.

FACCHINI, L. A., 1993. Trabalho e Saúde na Indústria da Alimentação de Pelotas. Relatório Técnico, apresentado ao CNPQ/OPS. Pelotas: Universidade Federal de Pelotas, Departamento de Medicina Social. (mimeo.)

FACCHINI, L. A., 1994. Uma contribuição da epidemiologia: o modelo de determinação social aplicado à saúde do trabalhador. In: Isto éTrabaIho de Gente? Vida, Doença e Trabal ho no Brasil (J.T. P. Buschinelli; L. E. Rocha \& R. M. Rigotto, orgs.), pp. 178-186, São Paulo: Vozes.

FACCHINI, L. A.; WEIDERPASS, E. \& TOMASI, E., 1991. Modelo Operário e percepção de riscos ocupacionais e ambientais: o uso exemplar de estudo descritivo. Revista de Saúde Pública, 25:394400.

FACCHINI, L. A.; DALL'AGNOL, M. M.; CARDOSO, A. S.; WEIDERPASS, E.; LIMA, R. C. \& BENVEGNÚ, L. A., 1992a. Trabalho e saúde em indústria de refrigerantes: o resultado do Modelo Operário. II Congresso Brasileiro de Epidemiologia. Belo Horizonte: Abrasco.

FACCHINI, L. A.; FASSA, A. G.; DALL'AGNOL, M. M. \& LUCIANI, F., 1992b. Trabalho e saúde em indústria de massas alimentícias: o resultado do Modelo Operário. III Congresso Brasileiro de Saúde Coletiva. Porto Alegre: Abrasco.
FACCHINI, L. A.; FASSA, A. G.; DALL'AGNOL, M. M.; LIMA, R. C. \& CARDOSO, A. S., 1993a. Trabalho e saúde em uma indústria de óleo comestível: o resultado do Modelo Operário. II Congresso Nacional da RedeIDA-Brasil. São Paulo.

FACCHINI, L. A.; FASSA, A. G.; LIMA, R. C.; DALL'AGNOL, M. M.; VIEIRA, M. \& FIALHO, E., 1993b. Trabal ho e saúde em um engenho de arroz: o resultado do Modelo Operário. Il Congresso Nacional da RedeIDA-Brasil. São Paulo.

FACCHINI, L. A.; FASSA, A. G.; LIMA, R. C. \& DALL'AGNOL, M. M., 1995a. Condições de trabal ho e saúde em uma indústria de laticínios: resultados do Modelo Operário. III Congresso Brasileiro, II Congresso Ibero-Americano el Congresso LatinoAmericano deEpidemiologia. Salvador: Abrasco.

FACCHINI, L. A.; FASSA, A. G.; DALL'AGNOL, M. M.; MACIEL, R. P. \& LIMA, R. C., 1995b. Condições de trabalho e saúde em um frigorífico: resultados do Modelo Operário. III Congresso Brasileiro, II Congresso Ibero-Americano e I Congresso LatinoAmericano de Epidemiologia. Salvador: Abrasco.

LAURELL, A. C., 1984. Ciência y experiencia obrera. Cuadernos Políticos, 41:63-83.

LAURELL, A. C., 1989. Manual: Conocer Para Cambiar - Estudio de la Salud en el Trabajo. México: Ed. Universidad Autónoma Metropolitana.

MT (MINISTÉRIO DO TRABALHO), 1994. Portarias números 24 e 25: Reformulação das Normas Regulamentadoras 7 e 9. Brasília: MT.

ODDONE, I., 1977. Ambiente di Lavoro: Ia Fabbrica nel Territorio. Roma: Editrice Sindicale Italiana. 